\title{
"El Dolo del Loco"
}

\author{
par Doctor E. Raúl Zattaroni (")
}

I.-introducción.

Las superestructuras inútiles, de apariencia inconmovible, pero que en realidad no son otra cosa que afirmaciones apriorísticas que, a fuerza de repetirse concluyen por ser tomadas como verdades incuestionables, se hallan en todas las ciencias. Puede afirmarse, sin temor a equivocación, que en la actualidad es relativamente sencillo detectarlas en cualquier rama del saber humano. No es extraño, por ende, hallarnos con semejantes superestructuras en las disciplinas jurídicas, con mucha más razón que en cualquier disciplina natural, toda vez que, por la propia naturaleza de la dogmática jurídica, se presta a este género de elucubraciones.

Alguna vez hemos sostenido que el "dolo del loco" era inadmisible. Sumergidos estábamos entonces en las ideas que hoy combatimos. (1) En efecto, si conforme a la superestructura tradicional concebimos al dolo co. mo perteneciente a la culpabilidad, y a la imputabilidad como capacidad de culpabilidad, afirmar que, en ciertos casos, el "loco" puede actuar con dolo, sería una monstruosidad lógica. Pero este esquema, que nos parecía tan simple, a poco andar y a la luz de métodos modernos, se nos reveló como sumamente endeble.

En marzo de 1965 comenzó en el Centro de Cólculo Electrónico de la Universidad Nacional Autónoma de México una investigación novedosa, consistente en verificar la posibilidad de aplicar la lógica matemática a la construcción dogmática de la teoría del delito, en lugar de utilizar la lógica tradicional o los procedimientos intuitivos. El resultado de esas investigaciones, apenas esbozado, creemos que es sumamente alentador y que permite afirmar no sólo la mera posibilidad de aplicar la lógica matemática a la elaboración dogmótica de la teoría del delito y del Derecho Penal, sino que viene a crear un método que se nos revela como altamente científico $y$ estricto.

Conforme a estas investigaciones, ensayaremos ahora la explicación del "dolo del loco", rectificando totalmente la posición que al respecto sostuviéramos cuando injustamente criticamos al "finalismo" en esta parte.

$\left.{ }^{\star}\right)$ Doctor en Ciencias Juridicas y Sociales por la Universidad Nacional del Litoral, Santa Fe (Argentina). - El Dr. Zaffaroni dictó una conferencia en nuestra Facultad durante su visita al Perú, $Y$ tuvo la gentileza de enviarnos este artículo para nuestra Revista. (Agosto, 1966).

(1) "La embriaguez en el Derecho Penal", en "Criminalia", Méjico, mayo de 1965.- 


\section{II.- El dolo en la conducta y ésta en el tipo.}

Largo sería historiar la evolución dogmática que vino a desembocar en la introducción de los elementos subjetivos del tipo. La introducción de lo subjetivo en el tipo fue una reacción antipositivista - filosóficamente hablando-, que rompió con el concepto tradicional de "acción" (2). La causalidad mecónica del positivismo filosófico, superada al tambalearse la física de Newton que le daba base, influyó en el Derecho Penal, el que, durante largas décadas, entendió a la cousalidad en el referido sentido mecánico. Esta es la teoría de la acción "causdl" - "ciega" le llama Welzel-. que fue magníficamente desarrollada por V. Liszt y V. Beling entre otros. De allí partió toda la corriente que, con más o menos variantes, concibió siem. pre a la conducta como un proceso que debe interpretarse conforme a las reglas de la causalidad mecánica. Pese a que Binding ya había criticada este concepto tradicional (3), se consideró que en este aspecto la dogmática era un mar calmo, mecido simplemente por alguna ligera brisa. Como el problema al que nos referimos está en la base misma de la construcción dogmática, toda ella era casi un espejo cristalino de serenidad, que llevó a afirmar la existencia de una discutible pax dogmatica, hoy desmentida por los hechos.

E] "finalismo" destruyó esta ilusión y esta posición cómoda. Muchos de sus enemigos jamás le perdonarán este pecado.

En efecto, la oposición a la acción causal introdujo el concepto de acción "finalista". En la teoría tinalista el dolo se desgaja de la culpabilidad y pasa a la conducta. Consideramos correcta esta posición si es que queremos deshacemos definitivamente de la superestructura lógica que, paradójicamente, parte del positivismo imperante en la época de su concepción. La teoría finalista, al dejar de lado al positivismo, retoma, en cierta forma, la filosofía de corte aristotélico. Nuestro nuevo modelo lógico-matemático confirma en este aspecto al "finalismo".

Según lo alcanzado en las investigaciones, la conducta no se nos presenta aislada del tipo, sino integrándolo, precisamente como su nucleo, su médula, su Kernel. Observemos que la conducta que nos interesa, desde el ángulo del Derecho Penal no es otra que la conducta típica. Si del amplísimo campo de las posibles conductas humanas, la ética se ocupa de un grupo limitado de las mismas y. el Derecho Penal, de un conjunto mucho más reducido aún que el de la ética, más unas pocas conductas que son indiferentes $\alpha$ la ética social, pero que se sancionan por razones políticas, veremos que el campo de interés del Derecho Penal no es el inmenso de la conducta humana, sino el limitadísimo de las conductas humanas tipificadas. Luego, en nuestro esquema,

$$
\text { conducta }=\text { conducta tipificada (conducta típica). }
$$

(2) Algunos autores prefieren hablar de "acto". Nosotros, siguiendo la terminología de Porte Petit, usaremos en lo sucesivo la voz "conducta".

(3) V. Juan Córdoba Roda, "Una nueva concepción del delito, la doctrina finalista", Ariel. Barcelona, 1963, p. 25. 
Conducta es la "actividad o inactividad voluntarias dirigidas a un resultado típico o atípico". Conforme a esta definición, sus elementos son: a) Voluntad; b) Actividad o inactividad. (4)

Con referencia al primer elemento, que es el que nos interesa a los. efectos de nuestro planteo, digamos que "voluntad es la capacidad de dirigir la actividad o inactividad" (4 bis). Esta voluntad, en los delitos dolosos, se dirige a la "concretización de la parte objetiva del Kernel" y se llama "dolo'. "El dolo incluye los llamados elementos subjetivos del tipo (distintos del dolo genérico), que algunos autores identifican con el dolo especifico y otros denominan elementos subjetivos del injusto". "En la estructura del delito que estamos exponiendo, solamente hay "dolo típico", en el que quedan comprendidos todos los elementos subjetivos requeridos por el tipo (5), de modc que, si en el caso concreto faltan los llamados "elementos subjetivos del tipo", estaremos frente $\alpha$ una atipicidad en virtud de que la $a u$ sencia de dolo típico originará una ausencia de conducta, Y siendo ésta elemento del tipo, su aspecto negativo configura la respectiva causa de atipicidad" (6).

Sintetizando: la conducta que nos interesa es la conducta típica que. necesariamente implica una voluntad denominada dolo en los delitos dolosos y que, por ende, debe ser también típico.

Como es fácil percibir, esta estructura altera en muchos conceptos que hasta hace poco eran ampliamente compartidos.

Por supuesto, también se hace necesario advertir que el dolo, tal como lo concebimos, está libre de todo juicio valorativo de reproche.

La nuestra es una postura normativista, pero al igual que el finalismo, es un normativismo extremo, pues llevamos el normativismo hasta sus últimas consecuencias, a diferencia de algunos autores normativistas que se quedan a medio andar. Ejemplo de ellos es Jiménez de Ásúa (7), quien afirma que sólo" el juicio de culpabilidad transforma la mera referencia psicológica de la intención, en dolo, es decir, en culpabilidad reprcchable y por tanto, normativa". Por nuestra parte, creemos que no es necesario y que, además, es profundamente inconveniente, escindir la conducta humana, o mejoi, la voluntad humana en dos partes, admitiendo una diferencia que a los efectos penales no es tal, entre intención y dolo (intención psicológica-intención psicológica jurídicamente valorada). En lugar, en nuestro esquema, hay una sola voluntad que está en la conducta típica, o sea, en la teoría del tipo. Luego, en la teoría de la culpabilidad queda sólo el reproche. Esa conducta típica le es reprochada al sujeto en virtud de la libertad con que obró, o sea que, hacemos que la libertad recobre la jerarquía.

(4) V. "Notas preliminares sobre un modelo lógico-matemático del Derecho Penal": aspecto jurídico: Olga I. de González Mariscal. Elpidio Ramírez Hernández y E. Raúl Zaffaroni; aspecto lógico-matemático, Lian Karp S., en "Derecho Penal Contemporáneo. N" 14. México, mayo-junio de 1966.

(5) Creemos oportuno advertir que la expresión "elementos subjetivos requeridos por el" tipo" no abarca la calidad que a veces es exigida en el sujeto activo, cuando menos en el sentido en que la empleamos en el texto.

(6) Op. y loc. cit.

(7) Tratado. T.V\%, p.414. 
que perdiera por obra del positivismo filosófico, el que también en este aspecto impactó al Derecho Penal, tratando de hacer desaparecer la libertad del Derecho. Pese a los denodados esfuerzos por erradicar la libertad, esta permaneció siempre en el centro de la problemática y hoy volvemos $a$ darle el lugar que le corresponde (8).

\section{III. - La imputabilidad en el sujeto activo $\mathbf{Y}$ éste cómo presupuesto típico constante del delito.}

Para la mayor parte de la doctrina, la imputabilidad es capacidad de culpabilidad o presupuesto de la misma, cunque otra corriente -casi todos los normativistas-, la consideran directamente como elemento de la culpabilidad. Por nuestra parte, ya intuitivamente habíamos criticado estas concepciones de la imputabilidad (9). Los argumentos provenientes de la aplicación de la lógica matemática vienen ahora a confirmar lo que entonces escribimos.

Hay elementos del tipo que, por ser previos a la realización de la conducta típica y por depender de los mismos la propia existencia del delito, son "presupuestos típicos del delito". Son, pues, elementos del tipo aunque no del delito, del que son presupuestos. Uno de estos presupuestos típicos del delito es el sujeto activo. Ádemás, este presupuesto típico es constante, o sea, que no puede faltar: no se concibe un tipo que no incluya al sujeto activo, puesto que no hay conducta si no hay sujeto de esa conducta.

Dejando de lado la discusión sobre la capacidad penal de las personas jurídicas y siendo piezas de museo o curiosidades anglosajonas los procesos a animales, no queda duda que, en todos los casos, debe tratarse de una conducta humana. Para que una conducta sea verdaderamente humana, no sólo requiere provenir de un ser humano, sino que exige la "voluntad", voluntad que, como ya dijimos, en los delitos dolosos se llama "dolo". Para que exista una tal voluntad (en adelante para simplificar hablaremos de "dolo"), es necesario que el sujeto esté naturalísticamente capacitado para ejercerla. o sea, que sea "capaz de dolo". Esta capacidad es un status, que, por definición es subjetivo, 0 sea, que el lugar donde debe ser estudiada, porque en él la hallamos, es en el sujeto activo.

Hay sujetos, como le explicaremos inmediatamente, que son incapaces de voluntad $y$, otros que, aunque tienen capacidad de voluntad, o sea, de conducta, son incapaces de culpabilidad, de ser sujetos de reproche.

Sintetizando, la imputabilidad es:

Capacidad $\left\{\begin{array}{c}\text { de conducta } \\ \text { Y } \\ \text { de culpabilidad }\end{array}\right.$

(8) Nos hemos ocupado del tema con más detalle en "La imputabilidad penal, problema de siempre", en Derecho Penal Contemporáneo, México, noviembre de 1965.

(9) "La imputabilidad, etc." cit. 
Conforme a esto, $y$ siendo " $A$ " capacidad de conducta y " $B$ " capacidad de culpabilidad, pueden darse los siguientes casos:

(1) $\bar{A} \cdot \mathrm{B}=$ imputabilidad;

(2) A. . B = inimputabilidad;

(3) $A \cdot B=$ inimputabilidad;

(4) $\bar{A} \cdot \mathbf{B}=$ caso prohibido.

El caso 2 es el del "dolo del loco". Preciso es aclarar, antes de continuar adelante, que la expresión "loco" DENOTA MUY POCO O NADA en la Psiquiatria actual, vale decir que no constituye ninguna entidad nosológicamente hablando, pero, como se ha difundido tradicionalmente, preferimos seguir empleándola.

El caso 1 no presenta mayor problema.

El caso 3 es el del sujeto que es directamente incapaz de conducta y por ende, nada tiene que ver aquí la culpabilidad. Si el sujeto es incapaz de voluntad, no se puede hablar de dolo en su conducta, porque ésta, como "conducta típica", no existe. Tales son por ejemplo los casos de epilépticos en las crisis, sean de grande o pequeño mal, el de los oligofrénicos profundos, el de los dementes en grados avanzados de la enfermedad, etc.

En lugar, en el caso 2, nos encontramos con un sujeto que es capaz de conducta y a la vez, incapaz de recibir el juicio de reproche. Decíamos intuitivamente (10), que la imputabilidad funciona como "linterna ciega", o sea, que aunque el sujeto es capaz de voluntad típica, desde la teoría del tipo llega a la teoría de la culpabilidad la advertencia de la imposibilidad de reprochar nada a ese sujeto, en virtud de que ha obrado sin libertad, siendo ésta la base del reproche.

Uno de los ejemplos, el más común del caso 2 ("dolo del loco"), es lo que en Psiquiatría se denomina "delirio" o "Delirio sistematizado". Se trata del individuo psicótico que, movido por las motivaciones que fueren, provenientes de su mundo psicótico, de las valoraciones imperantes en ese mundo subjetivo $\mathrm{Y}$ patológico, en ciertos casos sabe qué está haciendo en concreto, pero sin conciencia de la ilicitud de su conducta. Sumamente ilustrativo y vaștamente difundido, debido a que dió origen a las reglas que rigen la imputabilidad en el Derecho Penal Anglosajón, es el registrado en 1843 y conocido como caso M'Naghten. M'Naghten era un protestante del norte de Irlanda, psicótico, que en su delirio creía que S.S. el Papa y el líder del Partido conservador, Sir Robert Peel, conspiraba contra su vida. Se situó en la puerta de la residencia del Premier británico y, como no le conocía, disparó contra un secretario, Edward Drummond, a quien confundió con Peel.

En estos casos, sigue siendo válida la afirmación de Alexander Graf zu Dohna con referencia al error: quien sabe que mata, pero cree que puede hacerlo, mata con dolo. Contra la afirmación de Jiménez de Assúa, que dice: "El loco es capaz de voluntad, pero no de acciones dolosas" (11), di.

(10) Op. Y loc. cit.

(11) Tratado. T.Vo p. 486. 
ríamos: El loco, a veces, es capaz de loco, pero jamás puede ser sujeto de reproche.

Recordemos que en los delirios que comentamos, en los que el sujeto es capaz de dolo pero no de reproche, "el hecho delictuoso es un epílogo lógico de una elaboración anormal de ideas que llevan al enfermo a la convicción de que debe atacar a determinada persona. El raciocinio en estos casos es francamente delirante, y el alienado procede convencido de que realiza un acto justo, útil o necesario. El elemento ideoafectivo que lo dirige se basa en un anormal sentimiento de defensa, de venganza, de reparación, de justicia, de protección, en relación siempre con el color de su delirio". (12)

Tengamos en cuenta que "paranoia", que es justamente esta forma de delirio, en alemán significa "locura" (13) y que Kaepelin fue quien vió en ella una entidad perfectamente delimitada, circunstancia que hoy se discute mucho y en general, tiéndese a negarle autonomía a la paranoia. (14)

Uno de los más sonados casos de paranoicos llevados a los estrados judiciales fue el de Aurora Rodríguez y Carvalleira, registrado en España el 27 de junio de 1934. (15)

\section{Conclusión.}

El positivismo filosófico ha impactado al Derecho Penal fundamentalmente en dos puntos vitales: la conducta y la libertad. La primera se redujo a una causalidad mecónica y la segunda fue sistemáticamente negada o dejada de lado. En nuestra construcción volvemos a centrar el problema de la libertad humana como único punto de referencia para la reprochabilidad de la conducta, y además recuperamos la voluntad humana como unidad que es.

Sintetizando diríamos que la imputabilidad es un presupuesto subjetivo y típico del delito, consistente en la capacidad de actuar con voluntad libre.

(12) Nerio Rojas, Medicina Legal, El Ateneo, Buenos Aires, 1959, ps. 417-418.

13) Kurt Kohle, Psiquiatría, Alhambra, Madrid, 1964, p. 196.

(14) Está claramente expuesta la discusión en Kohle (cit.), como también el interesante caso del paranoico Wagner (pgs. 193 y sgts.)

(15) Ampliamente tratado. con las puntillosas correcciones a las distintas versiones del caso, puede verse en "La premeditación", de Etraín Torres Chávez, Casa de la Cultura Ecuatoriana, Quito, 1965, ps. 71 a 169. 